\title{
Thinking on Construction of Ecological Old-age Care Community in Xi'an in the Process of New Urbanization
}

\author{
Jian Ai \\ Xi’an Peihua University, Xi’an, China
}

\begin{abstract}
Keywords: The New Urbanization; Xi’an; Ecological old-age Care Community
\end{abstract}
\begin{abstract}
The new urbanization is an important carrier of ecological civilization construction, and ecological old-age care is the concrete manifestation of the perfect combination of the two, the proper meaning of the new urbanization connotation and an inevitable trend of its development. Based on the analysis of the connotation and relationship between the new urbanization and ecological old-age care, together with the current situation and existing problems of the current nursing institutions and ecological old-age care in Xi'an area, this paper discusses the major issues that should be noticed when constructing the ecological old-age care community in Xi'an and three main construction modes.
\end{abstract}

\section{Introduction}

Urbanization is the engine and link for expanding domestic demand and stimulating economic growth. The rapid development and advancement of urbanization in China has rapidly raised and improved China's economic society and the living standards of people. At the same time, disorderly expansion and unhealthy competition have also destroyed the ecological and social harmony, resulting in a series of problems such as weakening of the urban ecological environment and the waste of resources.

In order to get rid of many problems brought about by traditional urbanization in the course of development and realize the sustained, healthy and stable development of cities and towns and population, the 2012 Central Economic Work Conference put forward the concept of new urbanization for the first time, The 18th CPC National Congress clearly proposed that China will take the development path of new urbanization, and China issued the National New Urbanization Plan (2014-2020) in 2014, which proposed to integrate ecological civilization into urbanization and build green and smart cities. Therefore, the new urbanization is a new concept proposed in contrast with the traditional urbanization. It is guided by the Scientific Outlook on Development, in order to achieve the all-round, coordinated and sustainable development between man and nature, society, and ecology for the development goal of the optimized combination, coordinated development, and mutual promoting of urban and rural areas and the building of an ecologically livable, harmonious and equal society with the well-being of the people and sustainable development.

The new urbanization has the following characteristics: 1. It emphasizes ecological civilization, focuses on ecological protection, and integrates ecological civilization concepts and principles into the process of the construction of new urbanization; 2. It is with optimized, economical and intensive resources, optimized layout, friendly environment, ecological livability, and harmonious development; 3. It is guided by the Scientific Outlook on Development, people-oriented, with integration of urban and rural areas and coordinated development of towns, small, medium-sized and big cities. In a word, it reflects the scientific concept of development, the intensiveness of development mode, the coordination of development process and the human nature of development goal.

Based on the above: 1. Ecological old-age care is the proper meaning of the new urbanization connotation and important content of integration of urban and rural areas, layout optimization, friendly environment, ecological livability and harmonious development under the background of new urbanization. 2. Ecological old-age care is an inevitable requirement for the development of urbanization; 3 . The new urbanization is an important carrier of ecological civilization construction, 
and ecological old-age care is the concrete manifestation of the perfect combination of the two.

The "ecological old-age care community" belongs to the high-end level of community nursing and is the development and innovation of community nursing. According to the "theory of health promotion in places", it is the perfect integration of ecological old-age care and the continuous advancement of urbanization in the process of new urbanization. It relies on community service for home care of the elderly and institution for old-age care as the important support. With the efficient integration of various agencies and organizations such as government and civil society, the elderly population, ecological environmental protection, economy and policy are integrated into the nursing process, and community-based management and service system for the elderly is built, the design and utilization of the spatial layout of the entire ecological community is built with ecological concepts and ecological technologies so as to create an ecological old-age care conditions and environment for the elderly and realize the optimal allocation of needs and effective supply of ecological old-age care by means of the ecological old-age care function to achieve the mutualism of ecological resources and ecological relationship. In addition, self-service, mutual assistance and nursing services drive the silver economic growth, promote the transformation and upgrading of regional industrial economy, enhance regional competitiveness and popularity, so that to create opportunities, medical care, entertainment, school and services for the elderly.

\section{Main problems existing in Xi’an ecological old-age care community}

The statistics of the fifth and sixth census of Xi'an show that in 2010, the number of elderly people of 60 -year-old and above has increased by $42.9 \%$ than 2000 , with an increase of $52.93 \%$ of those aged 65 and above and a reduction of $28.83 \%$ of those aged $0-14$, and with an year-on-year increase of about $130 \%$ of people with college education (junior college or above). In 2014, the number of people over the age of 60 in Xi'an was 1,296,700. According to the research data of the system of elderly care service of 2017 in Xi'an, there are 1,521,900 elderly people over the age of 60 in our city (including Xixian New Area), accounting for $17.5 \%$ of the permanent resident population in Xi'an, of which 913,200 are 65 and above, accounting for 10.50\%; It is estimated that by the time of the realization of a moderately prosperous society in an all-round way in 2021, there will be 1,778,900 elderly people over the age of 60 in the city, accounting for $20.5 \%$ of the permanent resident population in Xi'an. ${ }^{\text {[1] }}$

From the above data we can see that the trend of population old-age care in Xi'an has been quite serious. And along with the continuous improvement of medical system reform in Xi'an, the rapid development of the Internet, the constant improvement of people's living standards, the continuous improvement of the quality of the aged groups, the continuous improvement of the average life expectancy in Xi'an, and the increasing number of the elderly population, the trend of population old-age care will be more serious. Therefore, the construction of ecological old-age care and community is one of the ways to solve social major contradiction in the new era, the needs of the elderly for a better life, strong practice of strictly implementing the mode of green production and lifestyle, and the inevitable development trend of the guarantee and improvement of livelihood for the elderly in the new era. However, the construction of ecological old-age care and community in Xi'an started late with inadequate policy support, and there are many existing problems as follows:

1) The system of elderly care service in Xi'an is developing rapidly, however, most of the current nursing institutions, including the community elderly care service centers, have poor infrastructure facilities, inadequate hardware and software facilities. And there is a large gap between institutions, layout of nursing institutions is unreasonable, and contradiction of the shortage of beds and unused beds co-exists. In addition, in the study, we found that part of the older people in districts and counties far away from the city have out-dated ideas and concepts, and most of them choose the home-based care. Therefore, the utilization rate of beds is higher in the areas more close to the city, such as Xincheng District and Lianhu District, whereas, the utilization rate of beds in districts and counties far away from the city center is relatively lower, such as Lantian, Zhouzhi and Huxian. Some community care service centers for the elderly have unitary service programs, inadequate 
functions, low utilization rate of resources, limited service range and low service quality. The ecological nursing community is the only path to promote the sustainable development of the service industry for elderly people in Xi'an, and its reasonable layout, featured construction mode, comprehensive, standardized and efficient service and management, can effectively solve the problems of current Xi'an nursing institutions and community care service centers for the elderly, and promote the nursing institutions in Xi'an to develop to the middle and advanced stage. However, at present, a few ecological old-age care projects under construction in Xi'an are currently in the early stages of theoretical research and construction, and they far cannot meet the market demands for ecological old-age care communities in Xi'an.

2) The elderly are full of endless desire for ecological old-age care, and some developers in Xi'an also launched feasibility study on ecological old-age care, however, as for current projects under construction, the only few ecological old-age care models are almost ecological old-age care complexes with high fees for the elderly with high income, which is intimidating to the groups with middle and lower income, and there is not feasibility analysis and research on the low- and middle-income elderly market for most working-class people. The far geographical planning site from the living area the elderly familiar or relatives the elderly familiar with, lack of community functions, and transport inconvenience, are unable to meet the emotional needs of the elderly. What's more, current institutions of care service for the elderly are with small venues, the poor environment, unprofessional service staff, inadequate public construction facilities for the elderly, the limited service population, and the unitary service content only in the cleaning and housekeeping, which is unable to meet the demand for health care follow-up, spiritual comfort, good ecology and so on. The above problems result in the weak sense of gain and identity of the elderly for nursing services.

3) The inadequate demand and supply of nursing staff of services for the elderly

The number of elderly people over the age of 60 in our city will reach 1.7879 million in 2020 . However, the number of nursing workers for the elderly in our city is only about 3400 at present, and with low level of nursing care, a relative shortage of professional nursing staff, the shortage of nursing staff and low attractiveness. For nursing staff, the long working hours, high intensity and heavy task in nursing, low social status and low pay, result in the imbalanced effort and reward and the weak sense of identity to the value of work. In terms of volunteer service, people's awareness of participation is not strong; ${ }^{\mathbf{2} \mathbf{1}}$ And the more the market is in short supply, the more the survival of the fittest is unable to be achieved through benign competition, and the more the quality of nursing care services and the quality of the nursing staff cannot be improved, only resulting in the vicious circle.

4) The people's Government of Xi'an also lacks relevant effective policies for the planning and construction of ecological old-age care communities, policies, laws and regulations and the implementation evaluation system of uniform services for the nursing care industry, and specific guidelines for implementation supporting policies and specific standards.

\section{Suggestions on the construction of Xi'an ecological old-age care community}

Based on the current situation and trend of new urbanization development in Xi'an and the serious development trend of aging population in Xi'an, the research team believes that it is imperative for Xi'an to build the ecological old-age care community. Carrying out research on the construction of old-age care community for the elderly in Xi'an is an important part of realizing a prosperous, democratic, culturally advanced, harmonious and beautiful socialist modern country, and the effective path to improve the sense of gain, happiness and security for the elderly, and to efficiently solve the contradiction between the ever growing demand for great life of the aging population and the inadequate and imbalanced development. Research team thinks that:

1) The people's Government of Xi'an should rely on the current nursing management departments and volunteers to increase publicity on ecological old-age care, with Xi'an Planning Bureau and legal research institutions jointly develop policy documents of Implementation Strategy on the Planning and Construction of Xi'an Ecological Old-age Care Community, and Policies, 
Laws and Regulations of Xi'an Ecological Old-age Care Community Service, and establish "special fund for the construction of Xi'an ecological old-age care community" to promote the infrastructure of Xi'an community nursing service center for the elderly.

2) To improve the salary of nursing service personnel in Xi'an, construct the salary supply mechanism and training mechanism for nursing service personnel in Xi'an, construct a professional and efficient contingent of ecological old-age care community service personnel, strengthen the inspection and assessment of the team, improve basic quality, technology and enthusiasm of volunteers, and promote the institutionalized and efficient development of the contingent of nursing service personnel in Xi'an.

3) According to the emotional and living needs of the elderly, combined with the development and distribution of nursing institutions in our city and the actual multilevel development of regional productivity, we will make overall plans and explore various development models to promote the construction of the ecological old-age care community in an all-round way and to change the imbalanced distribution of existing nursing resources for realizing the reasonable and optimal allocation of Xi'an ecological old-age care market resources. In terms of the construction mode of Xi'an ecological old-age care community, the research team thinks that:

(1) The low-carbon development mode of the transformation of current houses suitable for the elderly+community nursing service centers

The ecological old-age care community has a bright future, however, the initial investment is large. In addition, survey statistics of reporter in Xi'an Evening News show that more than $80 \%$ of elderly population in Xi'an still prefer home and community care, and these elderly people want get nursing care in their familiar environment and their own homes with their children. In addition, the layout of planning in main urban area of Xi'an has shaped and it is difficult to make major reconstruction in the existing basis. In view of the needs of the vast majority of elderly population in Xi'an, we think that the municipal government should focus on the ecological old-age care project as the key point of the benevolent project and people-benefit project. Therefore, we suggest to implement the low-carbon development mode of the transformation of current houses suitable for the elderly+community nursing care service centers. The government set up relevant organizations to determine the list of people who need help and support in the form of interview and investigation, adhering to the principle of one plan for one family to conduct the transformation of these old people's houses for the safety, accessibility, and cleanliness. In the meantime, the government should set up large-scale nursing care service bases in 11 districts and 2 counties and The Fengdong New City of Xi'an, which is managed by the municipal government. To set community nursing care service centers under each service base, and each community nursing care service center must be equipped with basic positions such as nursing housekeeper, nursing worker, and social workers, who will be managed and deployed to each nursing care service center. Nursing housekeeper should generally be some occupational nurses, responsible for some mild medical work, and for helping the elderly with cleaning, shopping, chatting, and life body testing. Nursing workers should be mainly responsible for the daily life care of the elderly. Social workers are mainly responsible for the mental health and entertainment life of the elderly. The advantage of this mode lies in that to conduct simple transformation of the existing living environment of the elderly on the basis of not changing the living environment site of the elderly, and maximize the utilization rate of existing resources to save resources. However, for managers, the service objects are too scattered and the imbalanced distribution of available resources is still not effectively solved.

(2) Mode of mixed-type ecological old-age care community+professional nursing care service institutions

With the gradual decline of the family old-age care function, the decline in traditional participation of children in old-age care, the market-oriented transformation of the old-age care mode, and the continuous increase of the old-age pension, the traditional consumption concept of the elderly gradually turns to new consumption concept with independence, initiative, freedom and health, and health maintenance. Mixed-type ecological old-age care community based on the above, is to set up old residential buildings suitable for the elderly (a new residential area is better) in 
ordinary residential houses or to build apartments for the elderly in an area with superior human environment and natural environment in Xi'an (eg, Baqiao District and Qujiang New District) to encourage these elderly people to live in in the form of renting, buying, loaning, or replacement (trade at a discount with the original house). Such old-age care communities rely on the resources around the community as the basis, community volunteers as supplement, manage uniformly through professional old-age care service institutions like the diversified and comprehensive old-age care and old-age aid service centers with the community to provide professional services for the elderly such as recuperation with CCRC (continuing care retirement community), rehabilitation, and nursing care. This mode is suitable for the new community and Dongcheng District and Xicheng District of Xi'an, which can not only meet the high-quality needs of the old-age care of middle-income families, but also can effectively improve the current imbalanced distribution of old-age resources in Xi'an, together with a variety of flexible and convenient replacement mode, will not bring great economic burden and pressure on the elderly, but also facilitate the government's effective management and assessment.

(3) High-end and independent mode of ecological old-age community complex

Such communities are often located in the suburbs with beautiful scenery and convenient transportation, and with both health maintenance and vacation functions. The development and construction combines local characteristics, and integrates the city life, community function, and ecological goals. This mode of ecological old-age community has diversified sources of funds and is suitable for the elderly with high education, low economic burden, strong concept of consumption and quality life, which is easier to form an aging industrialized commercial district, create highlights of the economic growth in the county and promote regional economic development. From the designing and planning of architecture to housing decoration, hardware and software equipment, catering, medical, finance, tourism, learning and re-employment, etc., the community is entirely elderly-centered, with the theme of housing for the elderly, with the modern service industry adapting to the ecological environment as the focal point of the community layout, and it is the integrated ecological old-age community with multidimensional stereoscopic landscape, professional medical management service system, diversified health promotion system, diversified cultural resources and environment system (such as senior club, cultural activity center and cultural activity station) and the supporting service system. As for the functional layout, it is divided into old-age health maintenance community and tourist resort. Health maintenance community can be divided into self-care community and nursing care community according to the physical condition of the elderly with different physical quality in different age groups. And the nursing care community can be divided into professional nursing area and special care area to provide a full range of nursing care services with medical, maintenance, nursing and rehabilitation service according to the different physical conditions of these elderly people. Tourist resort area can be divided into hotel and villa area of tourist resort to provide private doctors and body monitoring, health consultants, fitness recuperation and other special services for the elderly.

\section{Conclusion}

The 19th National Congress of the CPC pointed out that the construction of ecological civilization is a grand project of the sustainable development of the Chinese nation. The modernized nation to be built in China is the prosperous, democratic, culturally advanced, harmonious and beautiful modernization with the harmonious coexistence of man and nature as community of life. Xi'an should make full use of the ecological advantages of abundant natural resources and human resources in the region to respond positively to the requirements of the report of the 19th National Congress of the CPC, widely publicize and practice the concept of ecological old-age care, improve the system of ecological old-age care, and actively promote the principle of priority to conservation and protection and natural restoration-dominant. The construction of ecological old-age community will create the layout, industrial structure, mode of production and lifestyle of resources conservation and environmental protection, provide more quality ecological products, enhance the quality of ecological environment overall, meet the demand of the elderly for the beautiful 
ecological environment, promote the market-oriented operation of the old-age care industry, realize that lucid waters and lush mountains are invaluable assets, achieve the cooperative development of economic and social development and ecological environment protection, and promote the development of the silver economy and related industrial chains in Xi'an.

\section{Acknowledgements}

This paper is the phased achievement of the 2016 special scientific research project of Education Department of Shaanxi Province, "Study on the Construction of Xi'an Ecological Old-age Care Community in The New Urbanization" (Project No. 16JK2129).

\section{References}

[1] Data referred is calculated according to related statistics of the 08th edition, July 5, 2017, Xi'an: To Build Smart Old-age Care Ecological Chain, Xi'an Evening News and Xi'an Statistical Yearbook 2016.

[2] Zhang Xin, Study on Old-age Care Problems of Institutions in The Trend of Population Aging, Modern Business Trade Industry, No. 17, 2010. 